\title{
Chlorophyll dynamics around the Southern Channel Islands
}

\author{
Craig Gelpi ${ }^{1, *}$ \\ ${ }^{1}$ Catalina Marine Society, 15954 Leadwell St., Lake Balboa, CA 91406
}

\begin{abstract}
AвstRaCT.-We determine spatial and temporal dynamics of chlorophyll for the Southern California Bight through analysis of 10 years of chlorophyll product derived from the Moderate Resolution Imaging Spectroradiometer on the Earth Observing System satellite Aqua (MODIS-AQUA). Concentrating on the Southern Channel Islands, we find an island mass effect associated with San Nicolas; that is, some chlorophyll originates near the island. This signal is most evident during the fall after the typical spring phytoplankton bloom subsides. In contrast, there is a relative dearth of chlorophyll around Santa Catalina Island, and its seasonal modulation corresponds to the spring bloom, implying that the dynamics are much simpler for this island. Previous studies of temperature in the inner Southern California Bight near Santa Catalina indicate that a simple one-dimensional model of temperature diffusion explains well the seasonal and depth temperature modulations found there. We couple the temperature-derived vertical diffusion coefficient with nitrate measurements from California Cooperative Oceanic Fisheries Investigations (CalCOFI) cruises to make a simple one-dimensional model relating chlorophyll, insolation, and nitrate for Santa Catalina.
\end{abstract}

RESUMEN.-Determinamos la dinámica espacial y temporal de la clorofila, en la bahía del sur de California a partir de un análisis durante un período de 10 años cuyo resultado se derivó del espectroradiómetro de imágenes de resolución moderada del satélite Aqua del Sistema de Observación de la Tierra (MODIS-AQUA). Centrándonos en las Islas del Canal del Sur, hallamos un efecto de masa en la isla asociado a San Nicolás, es decir, que parte de la clorofila se origina cerca de la isla. Este indicador se vuelve más evidente durante el otoño, una vez que la típica floración primaveral del fitoplancton disminuye. Por el contrario, encontramos una relativa escasez de clorofila en la isla Santa Catalina y su modulación estacional corresponde a la floración primaveral, lo que significa que la dinámica es mucho más simple en esta isla. Estudios previos sobre la temperatura interna de la bahía del sur de California, cerca de Santa Catalina, indican que un modelo unidimensional simple de difusión de la temperatura explica bien las modulaciones en la temperatura, relacionadas a la estación y a la profundidad que allí se hallaron. Combinamos el coeficiente de difusión vertical derivado de la temperatura con las mediciones de nitrato de los cruceros de Investigaciones Cooperativas Oceánicas de California (CalCOFI, por sus siglas en inglés), para crear un modelo unidimensional simple que correlacione la clorofila, la radiación y el nitrato en Santa Catalina.

Results from a previous study (Gelpi and Norris 2008) indicate that the inner Southern California Bight exhibits simple temperature dynamics that can be explained as seasonal insolation forcing with one-dimensional vertical eddy diffusion. The diffusion coefficient was determined by an analysis of temperature measurements executed over the span of a decade. Hence, the oceanography of the inner bight (i.e., the ocean surrounding Santa Catalina Island) is relatively simple, and the region can serve as a natural laboratory for studying other processes, such as biological activity, in relatively uncomplicated conditions. The present study capitalizes on the previous findings by first examining whether the phytoplankton kinematic behavior in the region is similarly simple as the physical temperature dynamics and can be similarly modeled.

The islands in the Southern California Bight are divided into the Northern Channel Islands (lying along latitude $34^{\circ}$ ) and the Southern Channel Islands. The Santa Barbara Channel, bordered on the south by the Northern Channel Islands is biologically (in terms of phytoplankton) very active and is well studied. See, for example, work by Toole and Siegel (2001), Anderson et al. (2008), Kostadinov et al. (2007), and Brzezinski and Washburn (2011).

Here we emphasize the Southern Channel Islands: San Clemente $\left(32.90^{\circ} \mathrm{N}, 118.50^{\circ} \mathrm{W}\right)$,

*Corresponding author: craig@catalinamarinesociety.org 
Santa Catalina $\left(33.39^{\circ} \mathrm{N}, 118.42^{\circ} \mathrm{W}\right)$, geographically small Santa Barbara $\left(33.48^{\circ} \mathrm{N}\right.$, $119.04^{\circ} \mathrm{W}$, not considered further), and San Nicolas $\left(33.25^{\circ} \mathrm{N}, 119.50^{\circ} \mathrm{W}\right)$. These islands occupy an oceanographically different region than do the Northern Channel Islands, and as shown below, they exhibit significant biological activity differences amongst themselves, as well as with the Northern Channel Islands.

Compared to other areas off the West Coast, the inner bight is physically simpler for a variety of reasons. It is somewhat isolated from the main equatorward-flowing California Current, being located in a recirculation arm of the main current that flows northward and then diffuses through the various Channel Islands (Hickey 1992, fig. 1; Hickey 1993). It is sheltered from northern winds by the mountains that line the northern edge of the bight north of the Santa Barbara Channel, as well as by the Northern Channel Islands. Hence the inner bight experiences lower wind speeds that tend to be out of the southwest (Gelpi and Norris 2008). As a consequence, the inner bight does not experience the seasonal upwelling produced by Ekman offshore transport in response to the northerlies that is such a prominent phenomenon of the North and Central Coast; and, as the temperature study indicated, the inner bight is not as well mixed as the ocean in the Santa Barbara Channel or the waters farther offshore in the California Current. It forms a somewhat closed system. The northern areas of the West Coast also experience biological activity in fronts, filaments, eddies ( $\mathrm{Li}$ et al. 2012, Nagai et al. 2015), and upwelling regions that do not appear to be as significant in the inner bight. The relatively reduced mixing can be expected to influence the spring phytoplankton bloom and observed chlorophyll.

In the following sections, the average spatial and temporal chlorophyll modulations in the bight are described. The annual modulations are compared to other significant parameters such as temperature, stratification, light, and the nutrient nitrate. These modulations are then cast in the form of a diffusion equation relating chlorophyll and nitrate through the diffusion coefficient. The present work is similar in spirit to that of King and Devol (1979). They derived estimates of diffusion based on biological activity and nitrate uptake. In this work, we use previous diffusion measurements to describe nitrate distribution and biological activity. The quantitative success of the latter investigation, besides being of general interest, will bear on the suitability of using the Santa Catalina region as a relatively simple natural laboratory for studying complex biological processes.

\section{Methods}

Our approach is to compile and analyze long-duration time-series data to determine temporal and spatial correlations on a seasonal time scale between biological activity and its expected physical drivers. We use these correlations to investigate the type and complexity of the activity, as well as the choice and applicability of mathematical models needed to solidify its understanding. When warranted, the diffusion model of Gelpi and Norris (2008) is adapted to test whether simple concepts are applicable.

\section{Data Sources}

We employed data from a variety of sources to obtain phytoplankton biomass proxies and nutrients, and coupled these with data-based models for nonbiological mechanisms. For biomass, we used estimates of chlorophyll density determined from remote-sensing measurements of the Moderate Resolution Imaging Spectroradiometer (MODIS) instrument on the Earth Observing System satellite Aqua. We studied the nutrient nitrate $\left(\mathrm{NO}_{3}{ }^{-}\right)$using measurements made in situ during cruises of the California Cooperative Oceanic Fisheries Investigation (CalCOFI). Temperature models and gradients were based on the long-duration temperature measurements referenced above, while photosynthetic active radiation (PAR) was estimated from shortwave-radiation models.

ChlOROPHYLL DATA.-The chlorophyll product provided by the National Aeronautical and Space Administration (NASA) was used as a measure of biomass and biological activity. The MODIS Aqua sensor viewed the bight every 1 to 2 days in multiple spectral bands and with a spatial resolution of $250 \mathrm{~m}$. These data are processed by NASA to various levels of resolution, calibration, and product. The chlorophyll product is computed from a polynomial fit to the logarithm of the ratio of the blue to green remote-sensing reflectances, and represents upper-level chlorophyll densities. 


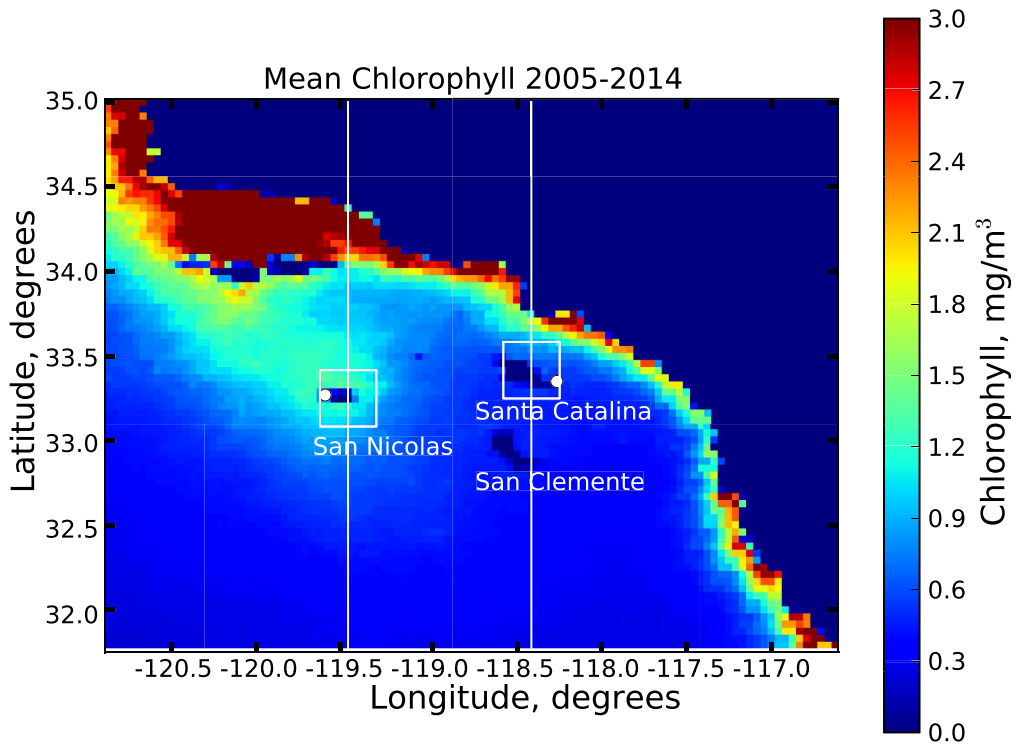

Fig. 1. Map of the study area indicating locations of quantitative analysis including CalCOFI sites (dots), latitudinal profiles, and averaging regions with spatial distribution of mean chlorophyll.

We downloaded the 8-day-composite, 4-kmcompressed Standard Mapped Image (Level 3 or L3) pixel data from 2005 to 2014 from a NASA website (https://oceancolor.gsfc.nasa.gov/ cgi/l3). The georeferenced 8-day-composite product provided good coverage with respect to cloud cover and relieved us of the computational burden necessary to georeference it that more fundamental and higher-resolution data products would require. For a more complete description of the sensor and the data retrieval algorithms, validation, and uncertainties, as well as subsequent processing to L3, see the website.

There are 46 data sets per calendar year, yielding $66.7 \mathrm{~GB}$ of data for the decade covering the earth. The 460 files were downloaded during the course of several years in conjunction with other studies, and during that interval there were changes to the retrieval algorithms. Hence the data used in this study have not been uniformly processed. However, because we are examining large trends with substantial averaging, we do not expect a significant sensitivity to the processing algorithms.

The downloaded data were uncompressed, and the region corresponding to the Southern California Bight was excised. This region extended from $116.75^{\circ} \mathrm{W}$ to $120.92^{\circ} \mathrm{W}$ and from $31.75^{\circ} \mathrm{N}$ to $35^{\circ} \mathrm{N}$. It is divided into 104 longitudinal and 78 latitudinal $1 / 24^{\circ}$ by $1 / 24^{\circ}$ pixels. Average chlorophyll density values are shown in Fig. 1, which serves as a map for this study, and indicates that a large portion of the pixels correspond to mainland areas. The excised data form a data cube (latitude, longitude, and time) available for signal processing.

NitRATE DATA.-Ocean chemical parameters were obtained from the CalCOFI website (www.calcofi.org) for cruises spanning the years 2005-2014, the same interval that corresponds to the retrieved chlorophyll product. Locations of the CalCOFI station positions can be found in CalCOFI reports and also obtained via links on the website. The IEHformatted files were decoded to supply the parameter values, including those for nitrate, which is analyzed here. Nitrate was measured via ultraviolet spectrophotometer techniques on retrieved water samples.

We emphasize data from 2 CalCOFI stations, one that represents San Nicolas Island (CalCOFI grid 87.50 , i.e., $33.27^{\circ} \mathrm{N} 119.62^{\circ} \mathrm{W}$ ) and another representing Santa Catalina Island (90.35, i.e., $\left.33.35^{\circ} \mathrm{N}, 118.25^{\circ} \mathrm{W}\right)$. Both are indicated on the map in Fig. 1. The temporal and depth sampling for these stations during the decade of interest are shown in Fig. 2. The CalCOFI station near San Nicolas is over the Santa Rosa-Cortez Ridge which limits the 


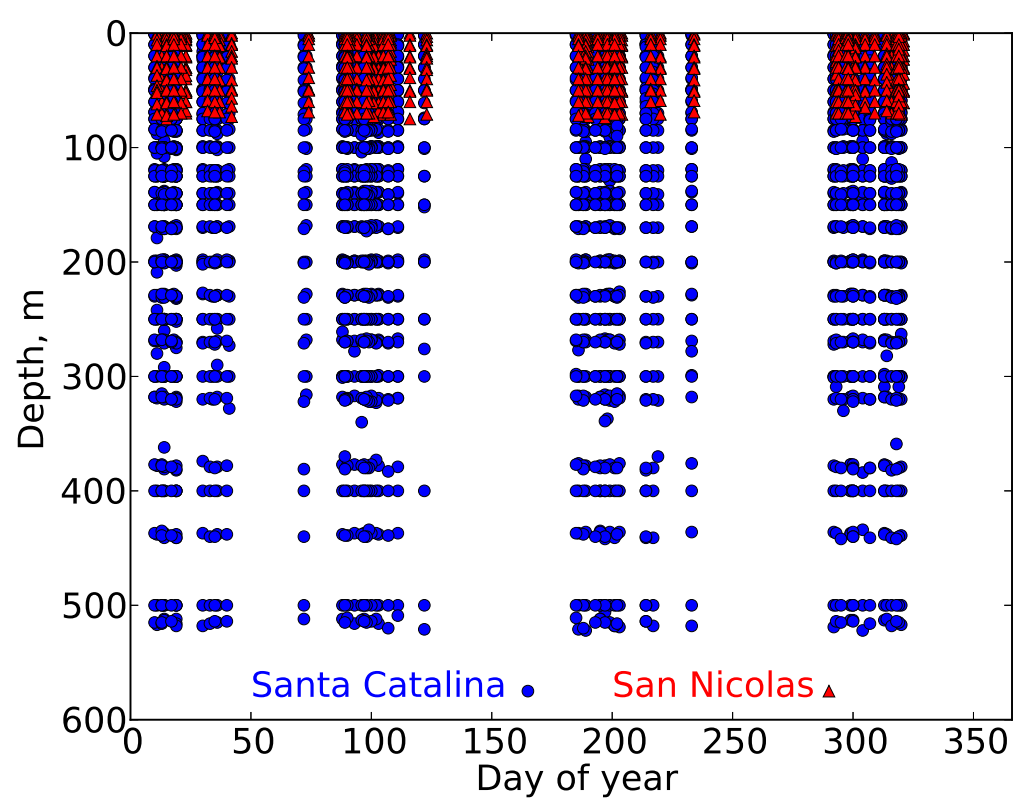

Fig. 2. Sampling pattern at San Nicolas (CalCOFI grid 87.5, red triangles) and Santa Catalina (CalCOFI grid 90.35, blue circles).

sampling depth to about $70 \mathrm{~m}$, whilst the sampling near Santa Catalina extended to much deeper depths, approximately $520 \mathrm{~m}$. The sampling times regarding the day of year were similar between the 2 islands and fell within 4 distinct periods. We group the sampling within these periods and, where warranted, report just 4 sampling times per year-namely, dayof-year 24, 100, 200, and 310 .

Temperature and Light models.-The temperature model valid for the inner bight is that derived in Gelpi and Norris (2008), the mathematical formulation and parameter values of which are given in Appendixes 1 and 2. The model was derived from physical considerations of vertical temperature diffusion, with diffusion coefficients determined from a decade of temperature measurements made around Santa Catalina Island, as well as from CalCOFI temperature measurements. The major data sets were measured from 1992 to 2001.

The PAR model is a sinusoidal fit to the approximation of the shortwave radiation model used as a component of the forcing for the diffusion equation in Gelpi and Norris (2008). The short-wave radiation model is for surface radiation flux as given by Kalnay et al. (1996) for the Santa Catalina Island location.

\section{Chlorophyll and Nitrate Analyses}

Chlorophyll ANALYSis.-Our analysis is directed toward determining the spatial and temporal averages of chlorophyll density (hereafter called chlorophyll) and its average kinematic behavior during the year. Seasonal samples were chosen to be the mean of 4 consecutive 8-day samples, providing 12 seasonal samples per calendar year per pixel. (The last seasonal sample has only two 8-day samples, and the last 8-day sample of the year available from the website is derived from only 5 or 6 days). The seasonal samples are plotted as a map of the bight.

Sources of chlorophyll were located with a spatial-gradient analysis. The chlorophyll value for each 8-day sample was normalized by the average chlorophyll values in the Southern California Bight so that an abundant year of chlorophyll would not dominate the calculations. Then the latitudinal and longitudinal gradients were computed by taking the difference between adjacent pixels to the pixel of interest in the appropriate directions. If either pixel value was zero, then the gradient was set to zero to avoid contamination of the gradient with land masks. The gradients computed for each sample period were averaged among all the temporal samples. 
A more finely resolved temporal examination of the chlorophyll seasonal dynamics was obtained by plotting an average latitudinal profile as a function of day of year with the average taken over the same day-of-year samples over the 10 years. Latitudinal profiles for Santa Catalina and San Nicolas were computed and their locations are shown in Fig. 1.

Finally, seasonal chlorophyll modulations about San Nicolas and Santa Catalina are summarized as sinusoidal fits to spatial-temporal averages of chlorophyll. Averages representing the islands were computed over 9-pixel $\times 9$ pixel regions $\left(36^{2} \mathrm{~km}^{2}\right)$ centered on the islands as shown by the white bordered squares in Fig. 1. These spatial averages were in turn averaged over the day-of-year samples for the decade. This spatial-temporal average was smoothed over 7 temporal samples in a cyclic fashion so that samples near the end of the year were smoothed with samples from the beginning of the year.

Nitrate analysis. - As stated above, nitrate analysis was limited to 2 CalCOFI stations nearest the islands of interest. For these stations, the seasonal changes to the nitrate depth profile were determined by averaging over appropriate intervals.

\section{Diffusion Analysis}

The analyses described above should indicate whether a simple diffusion model is applicable. The one-dimensional diffusion equation for nutrient is

$$
\frac{\partial N}{\partial t}-\kappa \frac{\partial^{2} N}{\partial z^{2}}=S(t, z)
$$

[Eq. 1]

where $N$ is a nutrient (here, nitrate), $t$ is time, $z$ is depth, $\kappa$ is the eddy diffusion coefficient, and $S$ is the combination of sources and sinks, including phytoplankton represented by chlorophyll. The temporal relationship among the physical drivers and nutrient and chlorophyll response will determine the form of $S(t, z)$ while the solution of Eq. 1 will provide numerical values to compare to measurements.

\section{RESUlTS}

\section{Chlorophyll and Nitrate Analyses}

Chlorophyll analysis.-For each pixel, the average chlorophyll over the decade of data examined is shown in Fig. 1. The color scale was chosen to emphasize chlorophyll for the Southern Channel Islands, and the chlorophyll values saturate the upper end of the color scale. The largest chlorophyll values are found in the Santa Barbara Channel, as consistent with the introductory statements. The productivity of this region is well known and has been studied by other researchers referenced above. Interestingly, there is also a region of large chlorophyll values that extends from the Santa Barbara Channel to San Nicolas Island. Other regions of large chlorophyll values are along the coast.

The seasonal behavior of chlorophyll is shown in Figs. 3 and 4, representing the first and second halves of the calendar year, respectively. In January (days 1-32; Fig. 3a), the values of chlorophyll that exceed $20 \mathrm{mg} \cdot \mathrm{m}^{-3}$ are along the coast and especially throughout the Santa Barbara Channel. In February (days 33-64; Fig. 3b), the region of chlorophyll with values exceeding $20 \mathrm{mg} \cdot \mathrm{m}^{-3}$ is not as extensive, but the region increases substantially during March and April (days 65-128; Fig. $3 \mathrm{c}-\mathrm{d}$ ), with a tongue of large chlorophyll values extending from the Santa Barbara Channel to the southeast and engulfing San Nicolas. Excluding the temporal activity in the Santa Barbara Channel and mainland coasts, we find that there is relatively more chlorophyll around San Nicolas but that there is nothing especially unusual about Santa Catalina or San Clemente islands.

For May through August (Fig. 3e-f and Fig. $4 \mathrm{~g}-\mathrm{h})$, chlorophyll values are seen to decrease with approach and entry into the summer months, but there remains noticeable chlorophyll around San Nicolas Island. The remaining Southern Channel Islands do not exhibit large chlorophyll values. This situation seems to be maintained for the remaining calendar months as shown in Fig. 4i-l.

The average chlorophyll gradient field is shown in Fig. 5. The largest gradients are along the coast and within or adjacent to the Santa Barbara Channel and Northern Channel Islands as expected. However, large gradients are also found adjacent to San Nicolas Island, and these are much larger than those surrounding Santa Catalina and San Clemente islands. The gradient vectors mostly are directed away from San Nicolas, indicating that the chlorophyll values are not maximal directly adjacent to the island. 

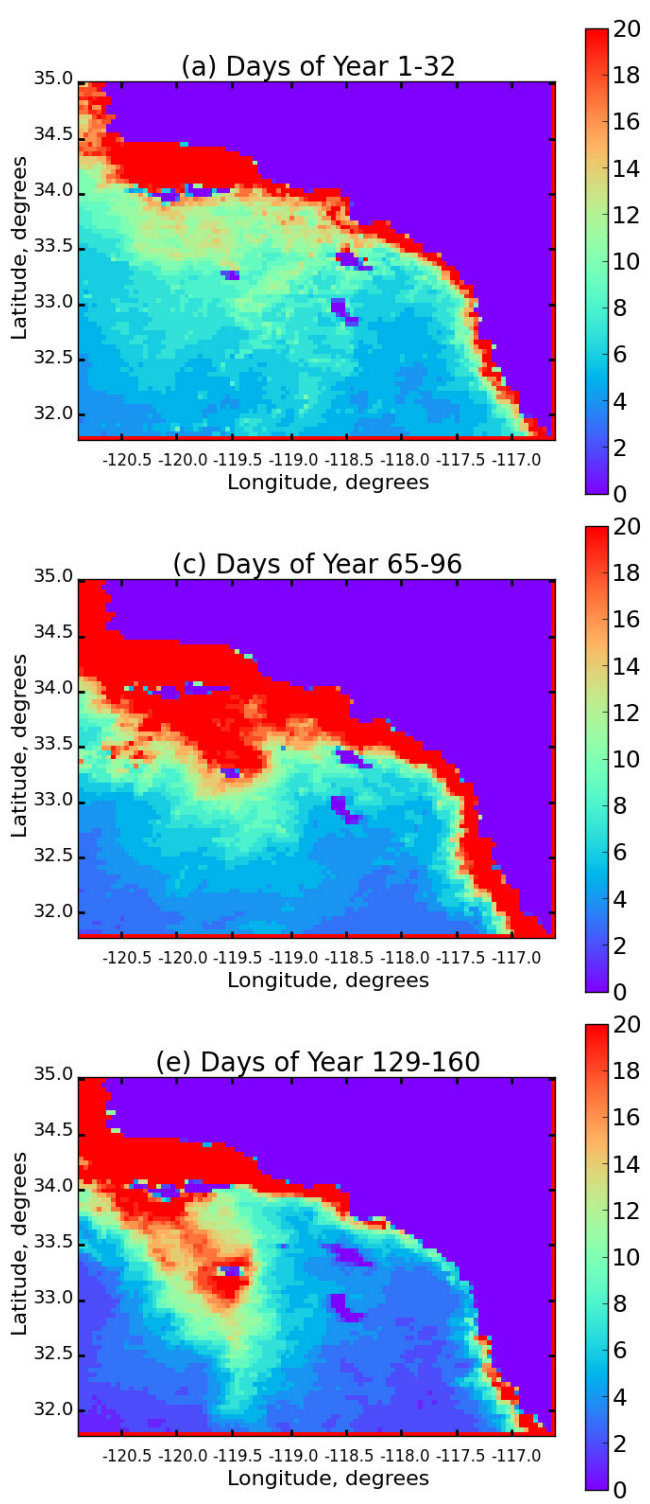
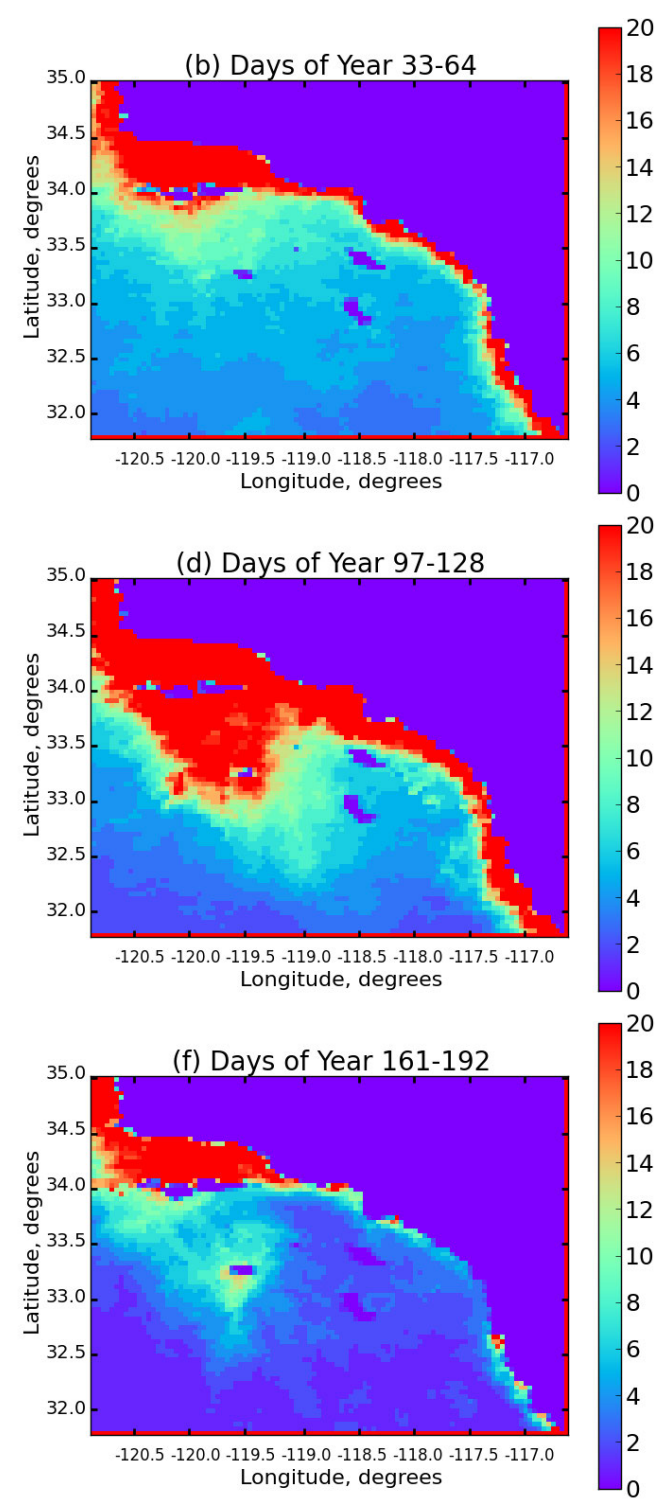

Fig. 3. Monthly averages of chlorophyll density, first half of year.

The temporal development of the chlorophyll latitudinal profile through Santa Catalina and San Clemente is shown in Fig. 6 and the corresponding one for San Nicolas is shown in Fig. 7. The latitudinal positions of the islands appear as chlorophyll values of zero. Values of chlorophyll about Santa Catalina appear to be well correlated with changes in chlorophyll near the mainland coast and are contiguous with it. And there is an interval near summer/fall when chlorophyll values are minimal. In contrast, the profiles through San
Nicolas indicate that there are times when noticeable chlorophyll exist at the island but are not contiguous with mainland values, with the implication that the chlorophyll originate in the region near San Nicolas. This is consistent with the spatial gradient analysis.

The area-averaged and smoothed time series, including a sinusoidal and mean fit, are shown in Fig. 8. No attempt was made to equilibrate for the different percentages of land within the area average. The fit parameters amplitude, phase, and mean for San 

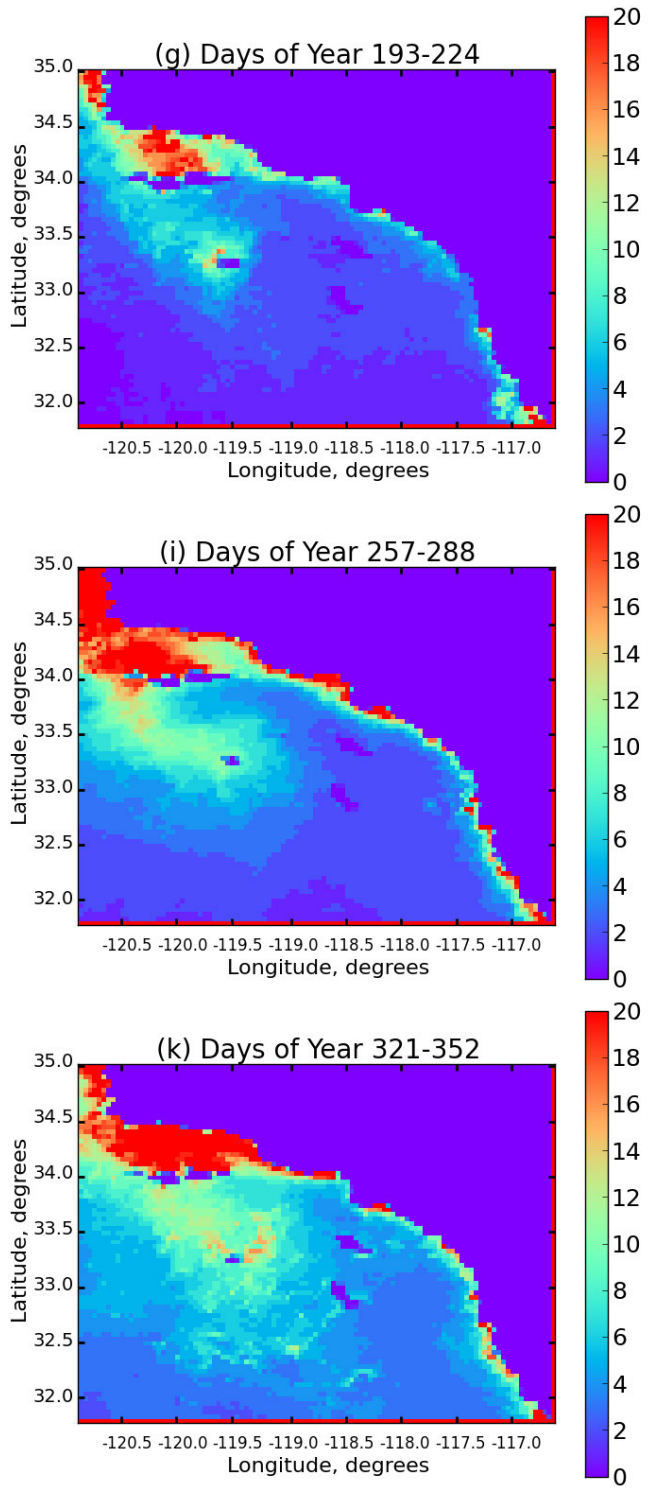
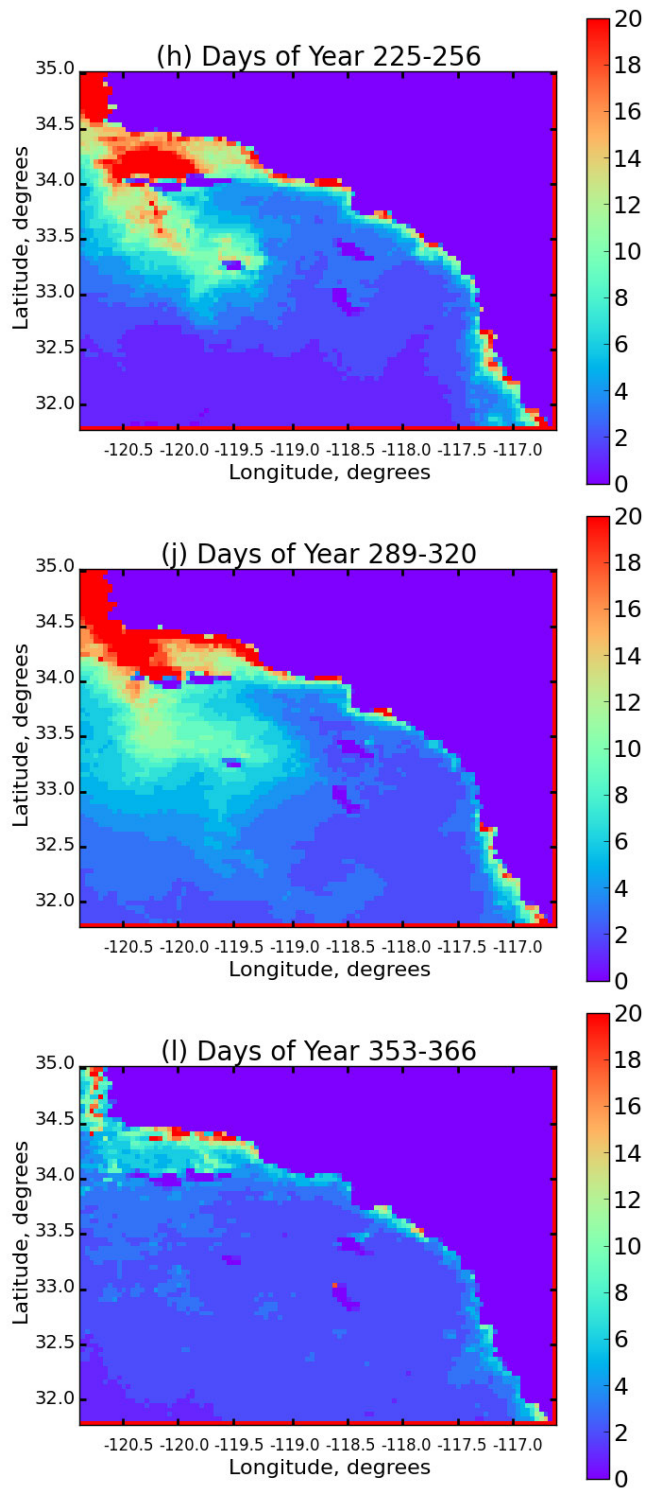

Fig. 4. Monthly averages of chlorophyll density, second half of year.

Nicolas are $0.38 \mathrm{mg} \cdot \mathrm{m}^{-3} ; 1.01$ radians, or 108 days; and $1.87 \mathrm{mg} \cdot \mathrm{m}^{-3}$, respectively. Similarly, the fit parameters for Santa Catalina are $0.36 \mathrm{mg} \cdot \mathrm{m}^{-3}$; 0.51 radians, or 59.7 days; and $1.04 \mathrm{mg} \cdot \mathrm{m}^{-3}$. As can be visually judged from the plot, (1) the spring-bloom maximum manifests earlier at Santa Catalina as compared to that at San Nicolas, (2) the bloom is greater at San Nicolas, and (3) San Nicolas has a greater mean chlorophyll value, though this latter point may be related to the ratio of land to ocean areas in the computation box, with the San Nicolas average containing more ocean pixels. Also, the chlorophyll modulation appears more sinusoidal at Santa Catalina than it does at San Nicolas.

Nitrate anALYSis.-An example of the CalCOFI nitrate data is shown in Fig. 9, where every sample between the beginning of the calendar year and day 50 is plotted versus depth for both the Santa Catalina and San Nicolas stations. The San Nicolas data reflect the aforementioned seabed depth and usually exhibit values larger than those at Santa 


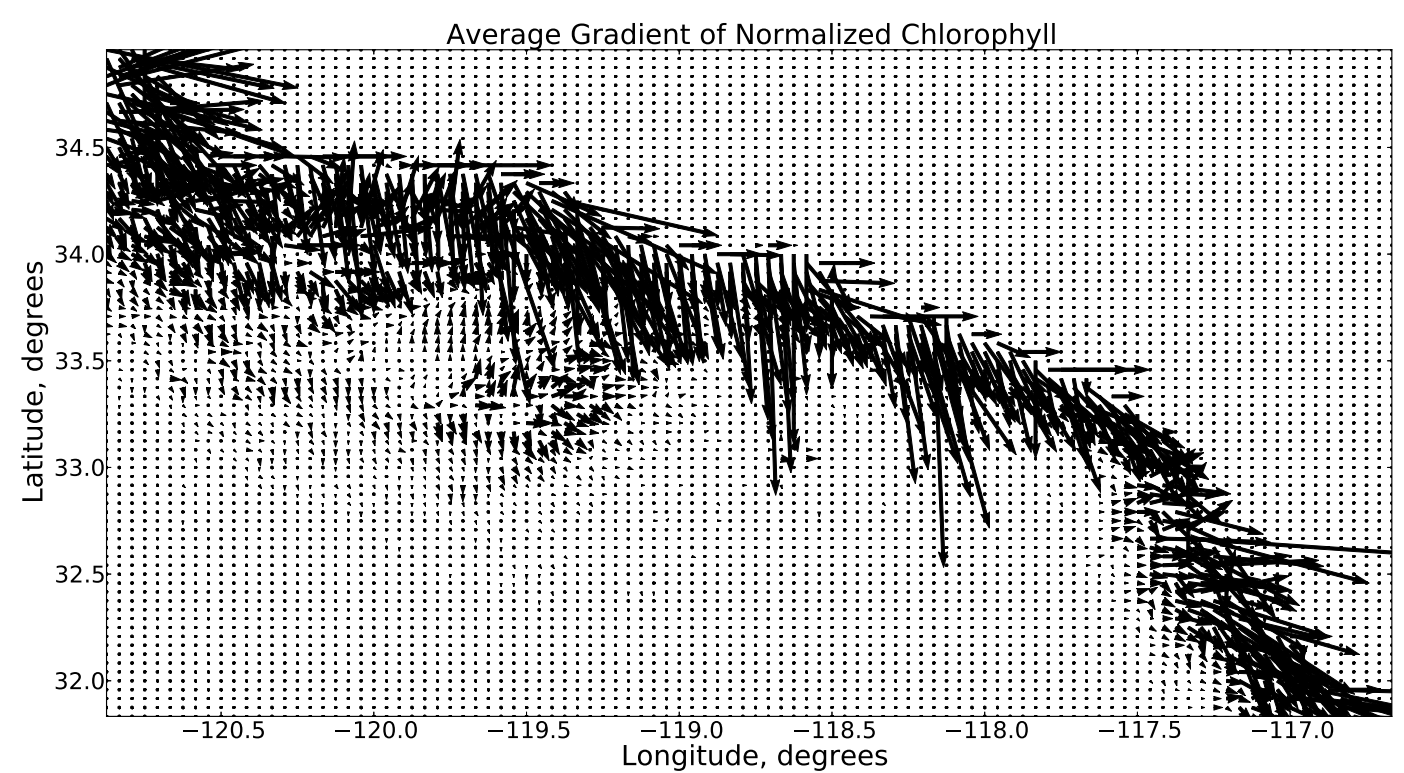

Fig. 5. Gradient of normalized chlorophyll values.

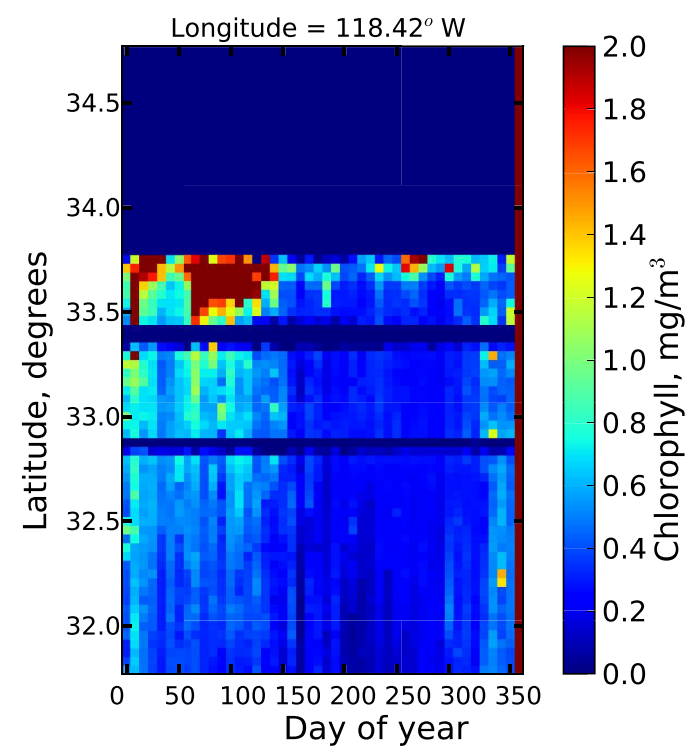

Fig. 6. Average latitudinal profile of chlorophyll through Santa Catalina and San Clemente versus day of year.

Catalina both at the surface and at sampled depths, implying that nitrate is not a limiting nutrient at this station and season.

In contrast, many nitrate values for Santa Catalina are zero near the surface (perhaps easier seen in later plots), implying that nitrate is a limiting nutrient there, as suggested by

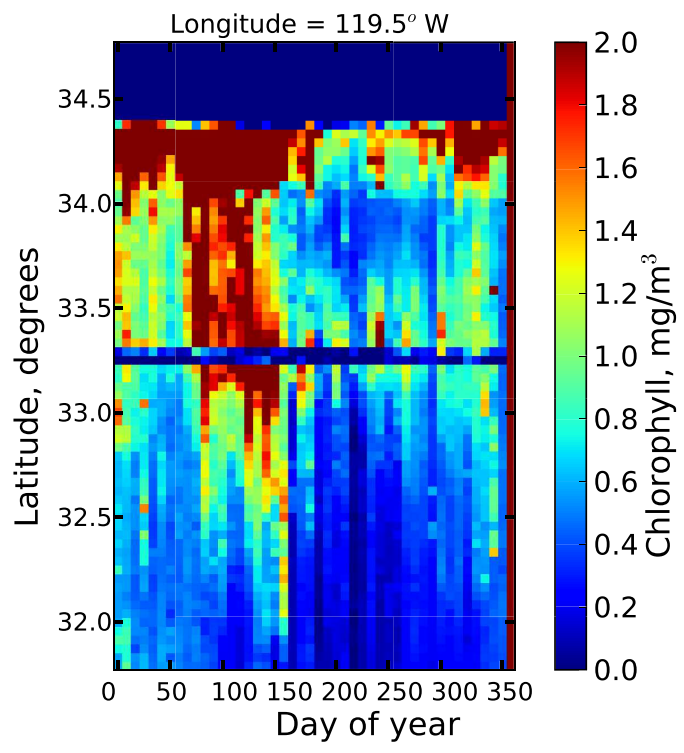

Fig. 7. Average latitudinal profile of chlorophyll through San Nicolas versus day of year.

Eppley et al. (1979). The nitrate vertical gradient changes with depth, being large near the surface $\left(\sim 0.20 \mu \mathrm{M} \cdot \mathrm{L}^{-1} \mathrm{~m}^{-1}\right)$ and decreasing in magnitude with depth. At a depth of $500 \mathrm{~m}$ the gradient is smaller, $<0.03 \mu \mathrm{M} \cdot \mathrm{L}^{-1} \mathrm{~m}^{-1}$, and nitrate values appear to approach an asymptote at about $40 \mu \mathrm{M} \cdot \mathrm{L}^{-1}$. 


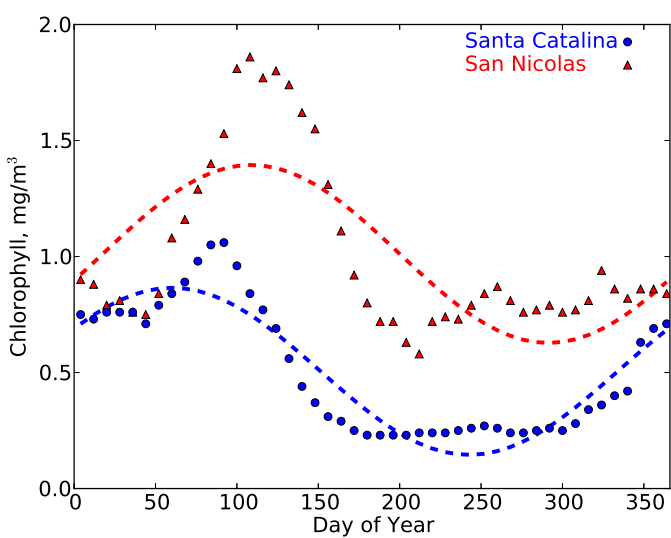

Fig. 8. Temporal modulation of average chlorophyll and sinusoidal fit for Santa Catalina, blue, and San Nicolas, red.

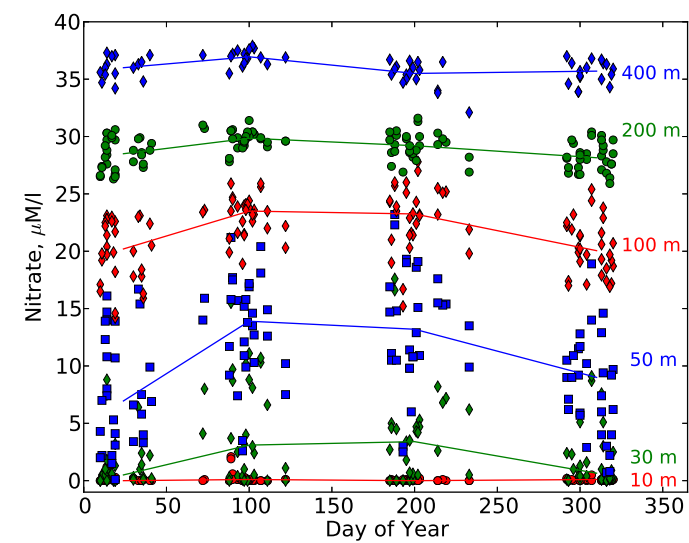

Fig. 10. Nitrate values measured at Santa Catalina for selected depths. Median values for depths and day-ofyear groups are represented by the solid lines.

We analyzed the seasonal changes at Santa Catalina by plotting the nitrate values versus day-of-year for the depths $10 \mathrm{~m}, 30 \mathrm{~m}, 50 \mathrm{~m}$, $100 \mathrm{~m}, 200 \mathrm{~m}$, and $400 \mathrm{~m}$ and show the results in Fig. 10. In addition to the data points, the median values of nitrate for each of the depths and 4 periods are plotted. Many of the values at $10 \mathrm{~m}$ are zero for each period, as is the median value, and the same is true for shallower depths (not shown). At $30 \mathrm{~m}$, many values including the median are nonzero. The medians also exhibit a seasonal dependence, being just above $0 \mu \mathrm{M} \cdot \mathrm{L}^{-1}$ at day 25 and day 310 , but with values of about $3 \mu \mathrm{M} \cdot \mathrm{L}^{-1}$ for the other 2 periods, hence being a $100 \%$

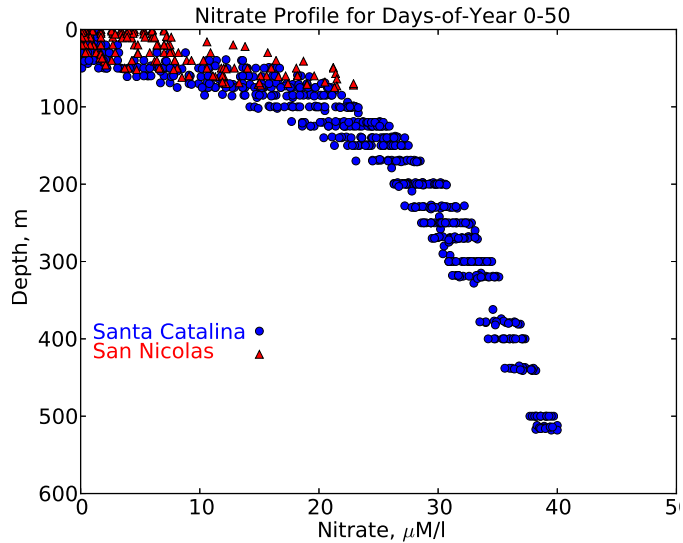

Fig. 9. Nitrate values versus depth obtained at San Nicolas and Santa Catalina for the first samples of the calendar year.

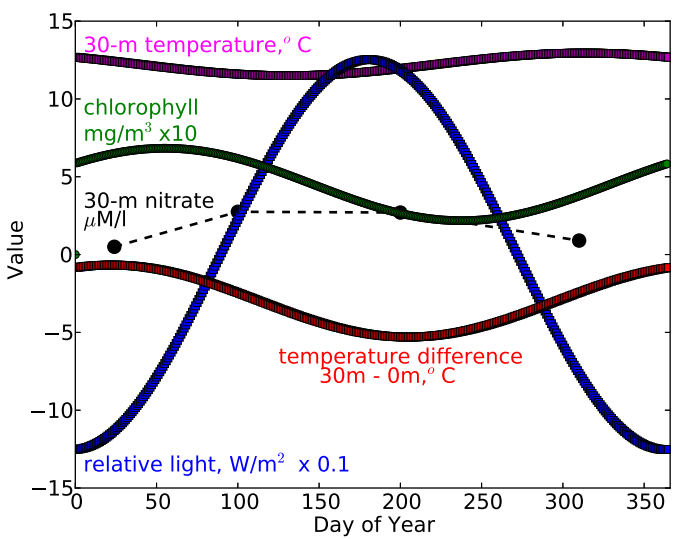

Fig. 11. Summary of seasonal variation at Santa Catalina for temperature, chlorophyll, nitrate, light, and temperature gradient.

modulation of the mean median value. A seasonal dependence is also found with the same phase at $100 \mathrm{~m}$ and with an almost $20 \%$ modulation of the mean median nitrate value, but at a depth of $400 \mathrm{~m}$, the dependence is diminished, being approximately a 3\% modulation of the mean median value.

Summary.-The various quantities described above vary to first order as a seasonal sinusoid. Nitrate may vary as a sinusoid, too, but the sampling is not often enough to uncover a yearly cycle (i.e., the Nyquist frequency is only 2 samples per year). We summarize the seasonal modulation of important data and parameters in Fig. 11. We plot the relative 
variation of shortwave radiation, which is closely related to the PAR, the temperature gradient represented as the modeled temperature difference between the surface temperature and temperature at $30 \mathrm{~m}$, the sinusoidal fit to the Santa Catalina chlorophyll product, and the median nitrate values at $30 \mathrm{~m}$. As the median values of nitrate were $0 \mu \mathrm{M} \cdot \mathrm{L}^{-1}$ at the surface, these values divided by $30 \mathrm{~m}$ yield the nitrate depth gradient of the upper surface layer.

By inspection we see that chlorophyll is in phase with neither temperature nor light. One would expect a sensitivity response to either light or temperature to be nearly immediate, resulting in the phase between chlorophyll and the forcing mechanism to be nearly the same. Hence chlorophyll is not responding in a significant way to these possible physical forcing functions and therefore is not limited by them. Chlorophyll does appear to be nearly in phase with the temperature vertical gradient (i.e., larger chlorophyll values when the gradient is small). Chlorophyll is also out of phase with the nitrate modulation and vertical gradient of nitrate. These observations suggest that vertical nitrate diffusion across the temperature gradient and the consumption of nitrate by phytoplankton are the major drivers of the chlorophyll-nitrate system. This is explored in further detail in the next section.

\section{Diffusion Analysis}

Diffusion Model.-We develop a model for nitrate (Eq. 1) based on the existing temperature model. Analysis presented by Gelpi and Norris (2008) showed that the temperature dynamics in the inner Southern California Bight (centered around Santa Catalina) are well described by a one-dimensional vertical diffusion equation with a constant diffusion coefficient of value $1.1 \times 10^{-4} \mathrm{~m}^{2} \cdot \mathrm{s}^{-1}$ for the upper ocean. This value is valid when and where there was sufficient signal (i.e., temperature gradient) to measure; else, it is not verifiable by temperature analysis. This value supports a collapse of the temperature gradient during winter, when the ocean surface loses energy via longwave thermal radiation to space as well as the transport of heat to deeper depths. Eddy diffusion could be much larger during this time but is not measurable due to lack of temperature gradient.

The eddy diffusion coefficient is expected to be the same for both heat and nitrate, though the source and sink functions are significantly different. For heat, the source is insolation while the sinks are thermal radiation, heat diffusion to deeper depths, and other minor contributors. The nutrient source is from deep depth and the sink is the consumption of nutrients by phytoplankton near the surface. We only consider an open system for nutrient; it is not recycled in the upper ocean.

To provide some intuition regarding the diffusion coefficient, we estimate the equilibration time, $T_{\text {eq }}$ (i.e., the time for $N$ to reach a steady state in the absence of time-varying sources or sinks). $T_{\text {eq }}$ can be estimated by using represented time and distance scalings. For example, setting $S$ to zero in Eq. 1 and using a vertical scale length of $l$, then

$$
T_{e q} \sim \frac{l^{2}}{\kappa} .
$$

Using the value for $\kappa$ stated above and a value of $30 \mathrm{~m}$ representing the phytoplankton region's depth for $l$ yields an equilibration time of $9 \times 10^{6} s \sim 100$ days, a seasonal scale length. Similarly, for a diffusion coefficient value that is 2 orders of magnitude larger, the equilibrium time is $\sim 1$ day, much faster than seasonal scales.

The nutrient sink is represented as

$$
S=\begin{aligned}
-\alpha \frac{\partial P}{\partial t} ; \frac{\partial P}{\partial t}>0 \\
0 ; \quad \frac{\partial P}{\partial t}<0
\end{aligned} \quad, \quad \text { [Eq. 3] }
$$

where $\alpha$ is the proportionality constant between nutrient and phytoplankton biomass proxy, $P$, which we represent with chlorophyll. We estimated $\alpha$ using an average chlorophyllto-carbon ratio for phytoplankton (Geider et al. 1997, 1998, Li et al. 2010) and then using the Redfield ratio of carbon to nitrogen, to determine the chlorophyll-to-nitrogen ratio. We find that $\alpha$ is $420 \mu \mathrm{M}$ nitrate to $1 \mathrm{mg}$ chlorophyll. This is simplistic as the carbon-tochlorophyll ratio may depend on temperature and light (Cloern et al. 1995). The qualifier in Eq. 3 that the sink is nonzero only when phytoplankton is increasing assumes the conversion of nitrate to other metabolic products that are not converted back to nitrate in the upper water column when the phytoplankton decrease. Using Eq. 3, Eq. 1 becomes 

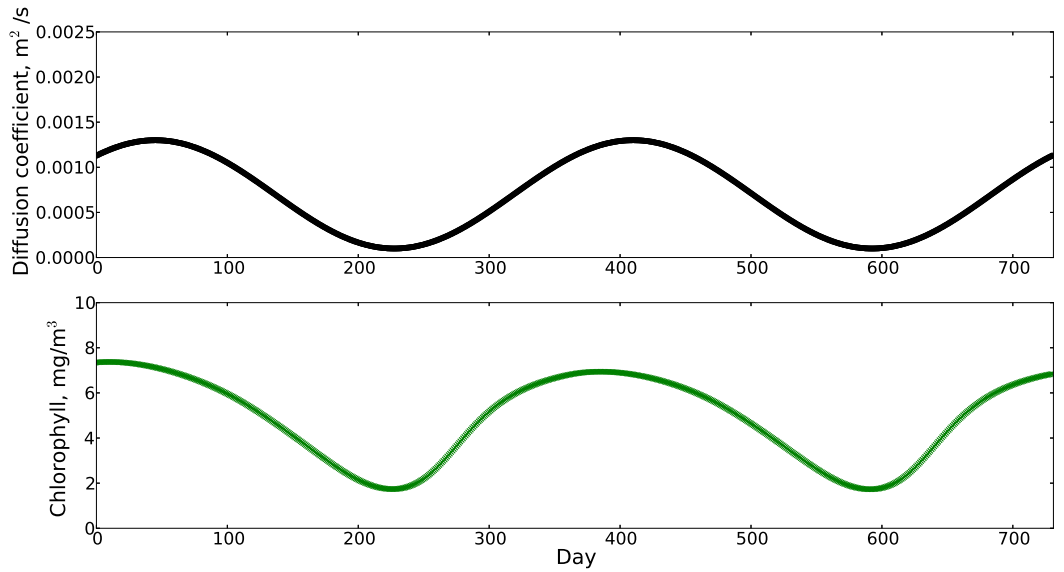

Fig. 12. Input modulation of diffusion coefficient (top) and resulting chlorophyll (bottom).

$$
\frac{\partial N}{\partial t}-\kappa \frac{\partial^{2} N}{\partial z^{2}}=-\alpha \frac{\partial P}{\partial t} ; \frac{\partial P}{\partial t}>0
$$

We represent the temporal change in phytoplankton via conventional terms and factors, namely

$$
\frac{\partial P}{\partial t}=(\mu F(T) G(L) H(N)-\beta) P(t),[\text { Eq. 5] }
$$

with $\beta$ being the mortality rate and $F, G$, and $H$ being the symbolic functional forms limiting the optimal growth rate $\mu$ for its dependence on temperature $(T)$, photosynthetically active radiation $(L)$, and nutrient. A review and attempt to standardize the functional forms is given by Tian (2006).

As stated previously, because $P$ is significantly out of phase with $L$, we can assume that phytoplankton are not light limited. A similar assumption can be made regarding $T$. Using this information, the dynamical equation for $P$ (Eq. 5) becomes

$$
\frac{\partial P}{\partial t}=(\mu H(N)-\beta) P(t),
$$

which can be combined with Eq. 4 to yield

$$
\frac{\partial N}{\partial t}-\kappa(t) \frac{\partial^{2} N}{\partial z^{2}}=-\alpha(\mu H(N)-\beta) P(t) .
$$

[Eq. 7]

In anticipation of the analysis below, we also let the diffusion constant in Eq. 7 vary with season.
There have been various proposed forms for $H$ (see Mann and Lazier 1996, Fennel and Neuman 2004). We choose the Monad relation, namely

$$
H(N)=\frac{N}{K_{N}+N},
$$

where $K_{N}$ is the half-saturation constant. Of course, more complicated expressions could have been chosen for $H$ that may change the interpretation, but the one chosen is simple, intuitive, and somewhat conventional.

Qualitative Solution.-As all the basic terms vary roughly as a sinusoid with annual frequency, an analysis of the phases of the sinusoids that solve Eq. 7 for the upper ocean may provide insight. First, the time derivative of $N$ must have the same phase $\alpha \beta P(t)$. That is, $P$ must be 90 degrees out of phase with $N$ to have the single-sinusoid terms of the diffusion equation equal, because $\alpha$ and $\beta$ are constant. This relationship is consistent with the results shown in Fig. 11. Also, the term HP must have the same phase as $\kappa N$. Because the Monad equation makes $H$ the same phase as $N, P$ must be the same phase as $\kappa$ and 90 degrees out of phase with $N$. Regarding the quantitative analysis of $\kappa$, we note that its minimum upper-ocean value must occur when $P$ is a minimum-that is, during the late summer. This is the time of year it was measured with the referenced temperature study.

Numerical solution EXample.-Equation 7 was solved numerically using nominal values for the parameters. The vertical-eddy 


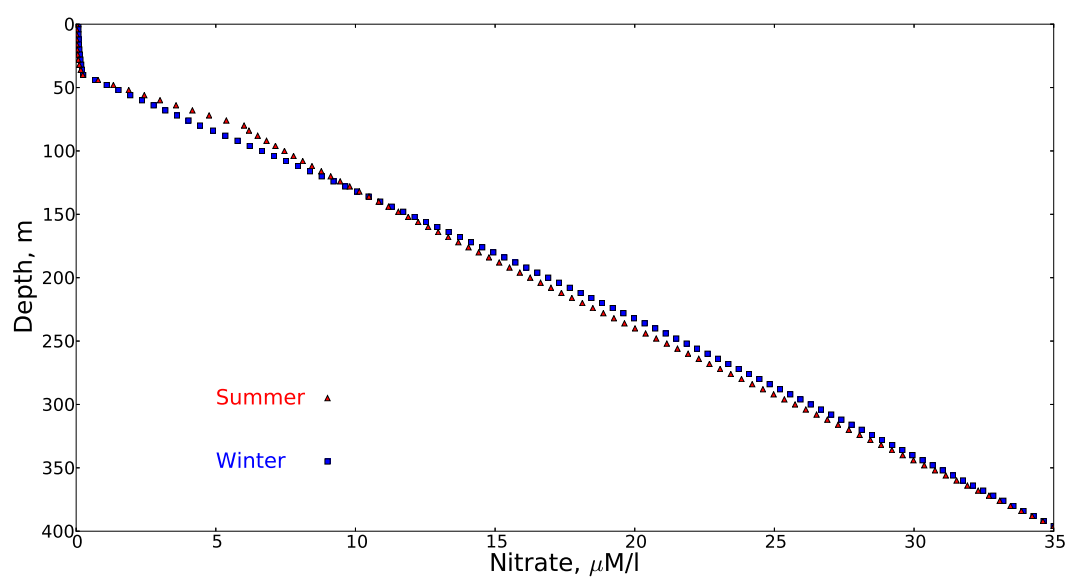

Fig. 13. Depth profile of nitrate output from diffusion model for day 1 and day 180 .

diffusion coefficient for the upper ocean $(<80-\mathrm{m}$ depth) was temporally modulated to be the measured value during summer $\left(0.0001 \mathrm{~m}^{2}\right.$. $\left.\mathrm{s}^{-1}\right)$ but increased to $0.0013 \mathrm{~m}^{2} \cdot \mathrm{s}^{-1}$ during the winter in recognition of upper-watercolumn-mixing storms. The input value of $\kappa$ for the upper ocean is shown in the top panel of Fig. 12. Below $80 \mathrm{~m}, \kappa$ was modeled as fixed with a value of $0.001 \mathrm{~m}^{2} \cdot \mathrm{s}^{-1}$. This fixed value represents the relative isolation of deeper depths with respect to weather phenomena producing large mixing yet little stratification inhibiting mixing.

Calculated phytoplankton effects are limited to be above a second depth $(40 \mathrm{~m})$ that is above the diffusion-coefficient transition. Because vertical transport of phytoplankton is not included in the calculation, the chlorophyll density is not permitted to decrease below a minimum value of $0.1 \mathrm{mg} \cdot \mathrm{m}^{-3}$. Otherwise, if the chlorophyll (phytoplankton) decreased to zero at a particular depth, there would be no mechanism to regenerate it there.

Nitrate values were initialized with a depth-independent value of $35 \mu \mathrm{M} \cdot \mathrm{L}^{-1}$ and then forced to satisfy a fixed boundary condition of $35 \mu \mathrm{M} \cdot \mathrm{L}^{-1}$ at $400 \mathrm{~m}$. Chlorophyll was initialized with the minimum chlorophyll value above $40 \mathrm{~m}$ and set to 0 below $40 \mathrm{~m}$. The other parameters appearing in the equation$m, \beta$, and $K_{N}$-were fixed as 2 per day, 1 per day, and $0.25 \mu \mathrm{M} \cdot \mathrm{L}^{-1}$, respectively. The growth and mortality rates are representative of those determined experimentally by Pasulka et al. (2015) for the Southern California Bight, using the technique of filtered seawater dilution followed by cytometric analysis.

When performing the integration Eq. 7 the temporal increment was continually modified to accommodate the temporally changing diffusion coefficient. To mitigate the effects of startup transients in the results, temporal integration was initiated the equivalent of a year before the outputs for the integration are shown.

The computed results for depth-integrated chlorophyll are shown in the bottom panel in Fig. 12, where the yearly modulation is exhibited and is in qualitative agreement with the results for Santa Catalina Island shown in Fig. 8, though the computed results provide values that are larger than the measured ones. The computed depth profile for nitrate is shown in Fig. 13 for 2 sample days: the first day of the calendar year and day 180 . These profiles are in qualitative agreement with the nitrate medians shown in Fig. 10; the dearth of nitrate at very shallow depths is reproduced; and the increase in nitrate between 40 and $80 \mathrm{~m}$ from winter to summer is a feature of the model. In general, the model and chosen parameters underestimate the measured values of nitrate for depths between 100 and $400 \mathrm{~m}$. Despite great uncertainties in the actual values of the input parameters, as well as the simplicity of the depth and seasonal dependences, the model is a reasonable representation of the chlorophyllnitrate measurements and modulations at Santa Catalina Island. 


\section{Discussion AND CONCLUSIONS}

Analysis of the chlorophyll seasonal variation in the Southern California Bight indicates that there are considerable differences among the major Southern Channel Islands, with San Nicolas exhibiting an island mass effect, while Santa Catalina and San Clemente show textbook behavior for phytoplankton blooms in temperate seas. We note that Caldeira et al. (2005) previously detected enhanced chlorophyll around San Nicolas using the Sea-viewing Wide Field-of-View Sensor (SeaWIFS) remotely sensed data.

Although the classical phytoplankton bloom phenomenon was explained many years ago by Sverdrup and described by Mann and Lazier (1996), the form and timing of the spring bloom varies significantly along the West Coast of the United States and the bloom off Santa Catalina is not typical for Southern California. A simple one-dimensional diffusion model for nitrate with phytoplankton growth as a nitrate sink and a seasonally varying vertical eddy diffusion coefficient qualitatively produces the features of the spring bloom found at Santa Catalina.

Regarding San Nicolas, there are some obvious speculations regarding the enhanced chlorophyll noted about the island. These include advection of high-chlorophyll-content water from the chlorophyll-rich Santa Barbara Channel, an island mass effect, and upwelling over the Santa Rosa-Cortez Ridge.

If the advection was slow enough, we could find it from inspection of Fig. 7 as an oblique structure in chlorophyll slanting downward toward the right as time increases, connecting the Santa Barbara Channel to San Nicolas. Although there is some hint of advection from the channel to the island, it is not conclusive. We have examined possible advection in rotated coordinates, such that an axis is along the Santa Rosa Ridge, but no advection was ascertainable. This could be because the advection is simply too rapid. The distance between San Nicolas and the channel, $100 \mathrm{~km}$, would require an advection speed of $<12.5 \mathrm{~km} \cdot \mathrm{d}^{-1}$ $\left(15 \mathrm{~cm} \cdot \mathrm{s}^{-1}\right)$ to be discernable with 8-day sampling. The advecting process would have to diminish southeast of San Nicolas, as the tongue of chlorophyll does not appear to extend substantially south of the island. Although high-speed advection cannot be ruled out, the fact that it would stop at San Nicolas makes advection from the Santa Barbara Channel seem unlikely.

Island mass effects are described by Hasegawa et al. (2004). They indicate that water rotating about an island can produce upwelling and therefore phytoplankton blooms. Dong and McWilliams (2007) have performed a numerical analysis of island wakes for islands in the Southern California Bight, but this vorticity is not found in their results. However, there is evidence of a cyclonic flow centered on San Nicolas from current retrievals using data from HF coastal radars (Largier 2016). This phenomenon may result in upwelling that enables the isolated, higher chlorophyll levels seen especially in Fig. 3e through Fig. 4h.

Finally, we note that water advected across the Santa Rosa-Cortez Ridge will be upwelled due to the shallow seabed along the ridge. This mechanism will provide relatively high levels of nitrate, consistent with what is shown in Fig. 9, and the upwelling will be confined to the shallow regions of the ridge, which exist between Santa Rosa Island and San Nicolas, as the ridge is much deeper southeast of San Nicolas. The plot of average chlorophyll shown in Fig. 1 is spatially consistent with the expected phenomena.

\section{ACKNOWLEDGMENTS}

The Catalina Marine Society thanks Karen E. Norris for coding the CalCOFI data reader, reviewing this work, and participating in many interesting discussions. We also thank NASA's Ocean Biology Processing Group for the chlorophyll product data downloaded between 2012 and 2016.

\section{Literature Cited}

Anderson, C.R., D.S. Siegel, M.A. Brzezinski, and N. Guillocheau. 2008. Controls on temporal patterns in phytoplankton community structure in the Santa Barbara Channel, California. Journal of Geophysical Research 113:C04038. https://doi.org/1029/2007J C004321

Brzezinski, M.A., AND L. Washburn. 2011. Phytoplankton primary productivity in the Santa Barbara Channel: effects of wind-driven upwelling and mesoscale eddies. Journal of Geophysical Research 116: C12013. http://doi.org/1029/2011JC007397

Caldeira, R.M.A., P. Marchesiello, N.P. Nezlin, P.M. DiGiacomo, and J.C. McWilliams. 2005. Island wakes in the Southern California Bight. Journal of Geophysical Research 110: C11012. 
Cloern, J.E., C. Grenz, and L. Vidergar-Lucas. 1995. An empirical model of the phytoplankton chlorophyll: carbon ratio-the conversion factor between productivity and growth rate. Limnology and Oceanography 40:1313-1321.

Dong, C., AND J. McWilliams. 2007. A numerical study of island wakes in the Southern California Bight. Continental Shelf Research 27:1233-1248.

Eppley, R.W., E.H. Renger, and W.G. Harrison. 1979. Nitrate and phytoplankton production in southern California coastal waters. Limnology and Oceanography 24:483-494.

Fennel, W., AND T. Neumann. 2004. Introduction to the modeling of marine ecosystems. Volume 72, 2nd edition. Elsevier Amsterdam, Netherlands.

Geider, R.J., H.L. MacIntyre, and T.M. Kana. 1997. Dynamic model of phytoplankton growth and acclimation: responses of the balanced growth rate and the chlorophyll $a$ :carbon ratio to light, nutrientlimitation and temperature. Marine Ecological Progress Series 148:187-200.

Geider, R.J., H.L. MacIntyre, and T.M. Kana. 1998. A dynamic regulatory model of phytoplanktonic acclimation to light, nutrients, and temperature. Limnology and Oceanography 43:679-694.

GelPi, C.G., AND K.E. NORRIS. 2008. Seasonal temperature dynamics of the upper ocean in the Southern California Bight. Journal of Geophysical Research 113: C04034. https://doi.org/10.1029/2006JC003820

Hasegawa, D., H. Yamazaki, R.G. Lueck, and L. SeuRONT. 2004. How islands stir and fertilize the upper ocean. Geophysical Research Letters 31: L16303. https://doi.org/10.1029/2004GL020143

Hickey, B.M. 1992. Circulation over the Santa Monica-San Pedro basin and shelf. Progress in Oceanography 30:37-115.

Hickey, B.M. 1993. Physical oceanography. Pages 19-70 in M.D. Dailey, D.J. Reish, and J.W. Anderson, editors, Ecology of the Southern California Bight. University of California Press, Berkeley, CA.

Kalnay, E., M. Kanamitsu, R. Kistler, W. Collins, D. Deaven, L. Gandin, M. Iredell, S. Saha, G. White, AND J. WoOlLEN, ET AL. 1996. The NCEP/NCAR 40-year reanalysis project. Bulletin of the American Meteorological Society 77:437-471

KING, F.G., AND A.H. Devol. 1979. Estimates of vertical eddy diffusion through the thermocline from phyto- plankton nitrate uptake rates in the mixed layer of the eastern tropical Pacific. Limnology and Oceanography $24: 645-651$.

Kostadinov, T.S., D.A. Siegel, S. Maritorena, and N. Guillocheau. 2007. Ocean color observations and modeling for an optically complex site: Santa Barbara Channel, California, USA. Journal of Geophysical Research 112: C07. https://doi.org/10.1029/ 2006JC003526

LaRgier, J. 2016. West Coast surface circulation: a decade of HF radar observations. EC44B-1242. 2016 Ocean Sciences Meeting, New Orleans, LA.

Li, Q.P., P.J.S. Franks, M.R. LANDRY, R. Goericke, and A.G. TAYLOR. 2010. Modeling phytoplankton growth rates and chlorophyll to carbon ratios in California coastal and pelagic ecosystems. Journal of Geophysical Research 115: G04003. https://doi.org/10.1029/ 2009JG001111

Li, Q.P., P.J.S. Franks, M.D. Ohman, and M.R. Landry. 2012. Enhanced nitrate fluxes and biological processes at a frontal zone in the southern California current system. Journal of Plankton Research 34:790-801.

ManN, K.H., AND J.R.N. LaZIER. 1996. Dynamics of marine ecosystems. 2nd edition. Blackwell Science, Cambridge, MA.

Nagai, T., N. Gruber, H. Frenzel, Z. Lachkar, J.C. McWilliams, and G.-K. Plattner. 2015. Dominant role of eddies and filaments in the offshore transport of carbon and nutrients in the California Current System. Journal of Geophysical Research Oceans 120:5318-5341

Pasulka, A.L., T.J. SAMO, AND M.R. LandRy. 2015. Grazer and viral impacts on microbial growth and mortality in the southern California Current Ecosystem. Journal of Plankton Research 37:320-336.

TIAN, R.C. 2006. Toward standard parameterizations in marine biological modeling. Ecological Modelling 193:363-386.

Toole, D.A., And D.A. Siegel. 2001. Modes and mechanisms of ocean color variability in the Santa Barbara Channel. Journal of Geophysical Research 106(C11): 26985-27000.

Received 23 January 2017 Revised 10 September 2017 Accepted 23 October 2017 Published online 22 February 2018 
ApPENDix 1. Temperature model for the inner Southern California Bight.

The model for the ocean temperature $T$, as modified slightly from that derived in Gelpi and Norris (2008), is a function of depth $z$ and time $t$. In complex notation, $i=\sqrt{-1}$

$$
\begin{aligned}
T(z, t) & =T_{0}(z)+T_{1}(z, t) \\
T_{0}(z) & =-C_{0} z+A \\
T_{1}(z, t) & =\frac{C_{1}}{2 i \alpha}\left[\frac{e^{-\beta z}-e^{-i \alpha z}}{i \alpha+\beta}+\frac{e^{-\beta z}}{i \alpha-\beta}\right] e^{-i \omega t} \\
C_{0} & =\frac{\mathrm{L}_{0} \beta}{c_{p} \rho \kappa} \\
C_{1} & =\frac{\mathrm{L}_{1} \beta}{c_{p} \rho \kappa} e^{i \phi} \\
\alpha^{2} & =\frac{i \omega}{\kappa}
\end{aligned}
$$

with $z$ in meters and $t$ in seconds. Parameters for the model are specified in Appendix 2.

APPENDIX 2. Parameter values for the temperature model.

\begin{tabular}{lll}
\hline Var. & Parameter & Value \\
\hline$\kappa$ & $\begin{array}{l}\text { Vertical eddy diffusion } \\
\text { coefficient }\end{array}$ & $1.1 \times 10^{-4} \mathrm{~m}^{2} \cdot \mathrm{s}^{-1}$ \\
$\beta$ & Light extinction & $0.435 \mathrm{~m}^{-1}$ \\
$\rho$ & Density of sea water & $1024 \mathrm{~kg} \cdot \mathrm{m}^{-3}$ \\
$c_{p}$ & Specific heat of water & $4186 \mathrm{~J} \cdot \mathrm{kg}^{-1}{ }^{\circ} \mathrm{C}^{-1}$ \\
$L_{0}$ & Mean surface flux & $82.7 \mathrm{~W} \cdot \mathrm{m}^{-2}$ \\
$L_{1}$ & Amplitude of surface flux & $125.3 \mathrm{~W} \cdot \mathrm{m}^{-2}$ \\
$\omega$ & Angular frequency of year & $2 \pi /\left(31.577 \times 10^{6} \mathrm{~s}\right)$ \\
$\varnothing$ & Insolation phase & $2 \pi(180.7 \mathrm{~d} / 365.25 \mathrm{~d})$ \\
$A$ & Surface mean temperature & $17.7^{\circ} \mathrm{C}$ \\
\hline
\end{tabular}

